American Journal of Applied Sciences 4 (6): 374-377, 2007

ISSN 1546-9239

(C) 2007 Science Publications

\title{
The Effect of Physical Refining on Palm Vitamin E (Tocopherol, Tocotrienol and Tocomonoenol)
}

\author{
${ }^{1,2}$ Chiew Wei Puah, ${ }^{1}$ Yuen May Choo, ${ }^{1}$ Ah Ngan Ma and ${ }^{2}$ Cheng Hock Chuah \\ ${ }^{1}$ Malaysian Palm Oil Board, Bandar Baru Bangi, 43000 Kajang, Selangor, Malaysia \\ ${ }^{2}$ Department of Chemistry, Faculty of Science, University of Malaya \\ Lembah Pantai, 50603 Kuala Lumpur, Malaysia
}

\begin{abstract}
This study reports the effect of physical refining on palm vitamin E including $\alpha$-tocopherol, $\alpha-, \gamma-$ and $\delta$-tocotrienols as well as $\alpha$-tocomonoenol. A method using HPLC with fluorescence detector using normal phase silica column is described. An isocratic elution with $n$-hexane/THF/2propanol (1000:60:4, by vol.) as mobile phase was used. The structure of the $\alpha$-tocomonoenol was determined using gas chromatography coupled with mass spectrometry. The composition of the vitamers were $\alpha$-tocopherol (14-17\%), $\alpha$-tocotrienol (22-24\%), $\gamma$-tocotrienol (49-53\%), $\delta$-tocotrienol (6-7\%) and $\alpha$-tocomonoenol (3\%) throughout the physical refining. The concentration of all vitamers in crude palm oil was $1273 \pm 18 \mathrm{ppm}$. The concentrations of all vitamers in degummed palm oil, bleached palm oil and deodorized palm oil were $1134 \pm 20$ ppm, $1095 \pm 18$ ppm and $1029 \pm 18$ ppm, respectively. This method provides fast and valuable information with minimal analysis time and no sample pre-treatment.
\end{abstract}

Key words: HPLC, palm oil, physical refining, $\alpha$-tocomonoenol

\section{INTRODUCTION}

Naturally occurring vitamin E is widely distributed in nature and is represented by a family of structurally related compounds (vitamers). The eight naturally occurring vitamers are $\alpha-, \beta-, \gamma-$ and $\delta$-tocopherols (T) and $\alpha-, \beta-, \gamma-$ and $\delta$-tocotrienols $\left(\mathrm{T}_{3}\right)$. The tocopherols are structurally characterized by a saturated phytol side chain in the chroman ring whereas the tocotrienols contain three double bonds in the side chain as shown in Fig. 1. The biological activities of vitamin $\mathrm{E}$ in different sources differ significantly with the richest sources of vitamin $\mathrm{E}$ in the diet being vegetable oils and their products. These include wheat germ oil, soybean oil, palm oil, corn oil and cottonseed oil $^{[1]}$.

Palm oil contains $600-1000$ ppm of vitamin $\mathrm{E}^{[2]}$. The composition of vitamin $\mathrm{E}$ in palm oil is characterized by the presence of $\alpha-\mathrm{T}(20 \%), \alpha-\mathrm{T}_{3}$ (22\%), $\gamma-\mathrm{T}_{3}(46 \%)$ and $\delta-\mathrm{T}_{3}(12 \%)^{[3]}$. Palm oil is unique among the common vegetable oils in having a high content of tocotrienols. Vitamin $\mathrm{E}$ is a potent antioxidant that protects the body against oxidative damage, notably cell membranes and cholesteroltransporting lipoproteins ${ }^{[4]}$. They are also useful in

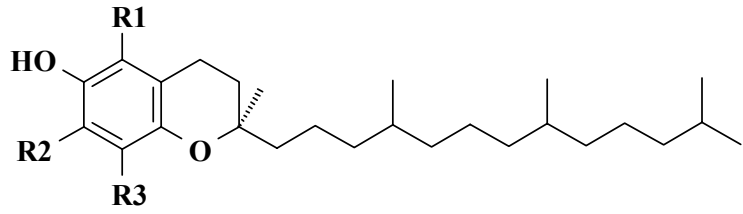

Tocopherol

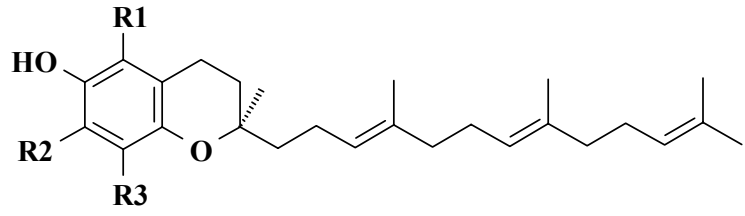

Tocotrienol

\begin{tabular}{llll}
\hline Isomer & $\mathrm{R} 1$ & $\mathrm{R} 2$ & $\mathrm{R} 3$ \\
\hline$\alpha-$ & $\mathrm{CH}_{3}$ & $\mathrm{CH}_{3}$ & $\mathrm{CH}_{3}$ \\
$\beta-$ & $\mathrm{CH}_{3}$ & $\mathrm{H}$ & $\mathrm{CH}_{3}$ \\
$\gamma-$ & $\mathrm{H}$ & $\mathrm{CH}_{3}$ & $\mathrm{CH}_{3}$ \\
$\delta-$ & $\mathrm{H}$ & $\mathrm{H}$ & $\mathrm{CH}_{3}$ \\
\hline
\end{tabular}

Fig. 1: Structures of tocopherol and tocotrienol

protection against skin damage and aging by UVradiation $^{[5]}$. Tocotrienols also exhibit cholesterollowering effect ${ }^{[6]}$ and inhibit growth of cancer cells ${ }^{[7]}$. Matsumoto et al. ${ }^{[8]}$ discovered a new vitamin $\mathrm{E}$

Corresponding Author: Chiew Wei Puah, No. 6, Persiaran Institusi, Bandar Baru Bangi, 43000 Kajang, Selangor, Malaysia, Tel: 603-87694400, Fax: 603-89262971 
constituent, $\alpha$-tocomonoenol, in palm oil but the amount was not quantified.

A large number of research papers published have reported the separation and quantification of the eight vitamers from various sources. The vitamin $\mathrm{E}$ are relatively non-polar and thus are chromatographed well using either normal phase or reversed phase chromatography ${ }^{[9]}$ using different detectors. The method of choice is the HPLC and the most commonly used detector for vitamin $\mathrm{E}$ analysis is the fluorescence detector with normal phase column. The use of GC for quantification has been reported ${ }^{[10]}$ but this technique has several drawbacks such as (i) pre-treatment of sample prior to injection, (ii) destruction of vitamin $\mathrm{E}$ which are heat-sensitive and (iii) a longer analysis time.

To-date, the vitamer, $\alpha$-tocomonoenol, was quantified using HPLC coupled with photo diode array detector $^{[11]}$. The drawback of the method is the sample pre-treatment involving centrifugation, followed by solvent distillation, which are laborious and timeconsuming. In addition, it only reported the quantification in crude palm oil, in addition to palm pressed fiber oil and phytonutrients concentrate.

In another study, the effect of bleaching and physical refining on $\alpha-T, \alpha-T_{3}, \gamma-T_{3}$ and $\delta-T_{3}$ has been reported ${ }^{[12]}$. However, it was not a detailed study as the effect of degumming was not reported. The effect of physical refining on the vitamer, $\alpha$-tocomonoenol has not been reported by any researcher.

This study reports a simplified method for the quantitative determination of palm vitamin $\mathrm{E}(\alpha-\mathrm{T}$, $\alpha-\mathrm{T}_{3}, \gamma-\mathrm{T}_{3}$ and $\delta-\mathrm{T}_{3}$ ) including $\alpha$-tocomonoenol, a new vitamer, using HPLC coupled with fluorescence detector.

\section{MATERIALS AND METHODS}

Crude palm oil (CPO), degummed palm oil, bleached palm oil and deodorized palm oil were obtained from the processing line of a local refinery. The reference materials of tocopherol and tocotrienol sets were purchased from Calbiochem-Novabiochem Corp. (La Jolla, CA). All solvents used were of HPLCgrade purchased from Merck (Darmstadt, Germany).

HPLC: The sample $(0.1 \mathrm{~g})$ was homogenized and weighed accurately into a $25 \mathrm{~mL}$ volumetric flask. The sample was dissolved with $n$-hexane and diluted to the mark. The HPLC system consists of a Agilent 1100 Series HPLC (Agilent Technologies, Palo Alto, CA, USA) complete with a quaternary pump, fluorescence detector and standard autosampler. A Zorbax SIL normal phase silica column $(5 \mu \mathrm{m}, 150 \mathrm{~mm} \times 4.6 \mathrm{~mm}$ i.d.) (Zorbax, USA) with mobile phase of $n$ hexane/THF/2-propanol (1000:60:4, by vol.) and flow rate of $1.0 \mathrm{~mL} \mathrm{m^{-1 }}$ were used. The compounds were detected at an emission wavelength of $326 \mathrm{~nm}$ and excitation wavelength of $292 \mathrm{~nm}$. Quantification was carried out using external standard calibration.

GC-MS: The instrument used was a Hewlett-Packard GC, model 6890 series coupled with a Hewlett-Packard Mass Selective Detector, model 6890 series. The capillary column used was an HP5 MS coated with (5\%-phenyl)-methylpolysiloxane (Agilent Technologies, Palo Alto, CA). The injector temperature was $245^{\circ} \mathrm{C}$ and GC-MS interphase temperature was $280^{\circ} \mathrm{C}$. The initial temperature of $100^{\circ} \mathrm{C}$ was held for 1 min and the final temperature of $280^{\circ} \mathrm{C}$ was held for 16 min. The ramping rate was $10^{\circ} \mathrm{C} \mathrm{min}^{-1}$. The mode of ionization was EI with an ionization voltage of $70 \mathrm{eV}$ was used.

\section{RESULTS AND DISCUSSION}

A typical HPLC profiles of CPO obtained is shown in Fig. 2. The chromatogram shows a good baseline separation of the vitamers. It illustrates at least five identifiable peaks which corresponds to $\alpha-\mathrm{T}$ (4.962 $\min$ ), $\alpha$-tocomonoenol (5.274 $\mathrm{min}), \alpha-\mathrm{T}_{3}$ (5.935 $\mathrm{min}$ ), $\gamma-\mathrm{T}_{3}(9.386 \mathrm{~min})$ and $\delta-\mathrm{T}_{3}(12.585 \mathrm{~min})$. The total analysis time was less than 15 mins. The presence of an unknown peak between $\alpha-\mathrm{T}$ and $\alpha-\mathrm{T}_{3}$ was observed. The component was isolated and identified using gas chromatography coupled with mass spectrometry. The component was confirmed to be $\alpha$-tocomonoenol.

The structure of the new vitamer, $\alpha$-tocomonoenol is shown in Fig. 3. The presence of $\alpha$-tocomonoenol was attributed as a biosynthetic intermediate along the reductive pathway to $\alpha-T$ from $\alpha-T_{3}$ in higher plants $^{[13]}$. Thus, the presence of one or two double bonds in the phytol side chain is possible. The mass spectra of the $\alpha$-tocomonoenol revealed the molecular ion of 428, 2 mass units less than $\alpha-\mathrm{T}$. Fragment at $\mathrm{m} / z$ of 205 is attributed to the benzopyranol ion $\left(\mathrm{C}_{13} \mathrm{O}_{2} \mathrm{H}_{17}\right)^{+}$ without the isoprenoid side chain and $\mathrm{m} / z$ of 165 is attributed to its characteristic tropylium ion $\left(\mathrm{C}_{10} \mathrm{O}_{2} \mathrm{H}_{13}\right)^{5+}$.

The successful separation and identification of the vitamers enable their quantification. The quantification of the vitamers in CPO, degummed palm oil, bleached palm oil and deodorized palm oil were carried out using external standard calibration. However, the external standard of $\alpha-\mathrm{T}$ was used to quantify $\alpha$-tocomonoenol with the assumption that all $\alpha$ - vitamers responded similarly. A consistent repeatability and high precision of the vitamin E concentration in CPO, degummed palm oil, bleached palm oil and deodorized palm oil were obtained with low SE for each vitamer (Table 1). 
Am. J. Applied Sci., 4 (6): 374-377, 2007

Table 1: Concentration $\left(\mathrm{mg} \mathrm{kg}^{-1}\right)$ of vitamin E during physical refining of palm oil

\begin{tabular}{|c|c|c|c|c|c|c|}
\hline \multirow{2}{*}{ Sample } & \multicolumn{6}{|c|}{ Concentration $\left(\mathrm{mg} \mathrm{kg}^{-1}\right)$} \\
\hline & $\alpha-T$ & $\alpha-T_{3}$ & $\gamma-T_{3}$ & $\delta-\mathrm{T}_{3}$ & $\alpha$-tocomonoenol & Total \\
\hline Crude palm oil & $212 \pm 6$ & $308 \pm 4$ & $630 \pm 5$ & $83 \pm 2$ & $40 \pm 1$ & $1273 \pm 18$ \\
\hline Degummed palm oil & $168 \pm 4$ & $265 \pm 7$ & $587 \pm 6$ & $77 \pm 1$ & $37 \pm 2$ & $1134 \pm 20$ \\
\hline Bleached palm oil & $157 \pm 2$ & $245 \pm 7$ & $585 \pm 3$ & $76 \pm 4$ & $31 \pm 2$ & $1094 \pm 18$ \\
\hline Deodorized palm oil & $158 \pm 6$ & $245 \pm 4$ & $533 \pm 4$ & $64 \pm 2$ & $29 \pm 2$ & $1029 \pm 18$ \\
\hline
\end{tabular}

Note: Mean value of three replicates

Abbreviations: $\alpha$-T, $\alpha$-tocopherol; $\alpha-\mathrm{T}_{3}, \alpha$-tocotrienol; $\gamma-\mathrm{T}_{3}, \gamma$-tocotrienol; $\delta$ - $\mathrm{T}_{3}, \delta$-tocotrienol

Table 2: Composition (\%) of vitamin E during physical refining of palm oil

\begin{tabular}{|c|c|c|c|c|c|}
\hline \multirow{2}{*}{ Sample } & \multicolumn{5}{|c|}{ Composition (\%) } \\
\hline & $\alpha-\mathrm{T}$ & $\alpha-T_{3}$ & $\gamma-\mathrm{T}_{3}$ & $\delta-\mathrm{T}_{3}$ & $\alpha$-tocomonoenol \\
\hline Crude palm oil & 17 & 24 & 49 & 7 & 3 \\
\hline Degummed palm oil & 15 & 23 & 52 & 7 & 3 \\
\hline Bleached palm oil & 14 & 22 & 53 & 7 & 3 \\
\hline Deodorized palm oil & 15 & 24 & 52 & 6 & 3 \\
\hline
\end{tabular}

Abbreviations: $\alpha$-T, $\alpha$-tocopherol; $\alpha-\mathrm{T}_{3}, \alpha$-tocotrienol; $\gamma-\mathrm{T}_{3}, \gamma$-tocotrienol; $\delta$ - $\mathrm{T}_{3}, \delta$-tocotrienol

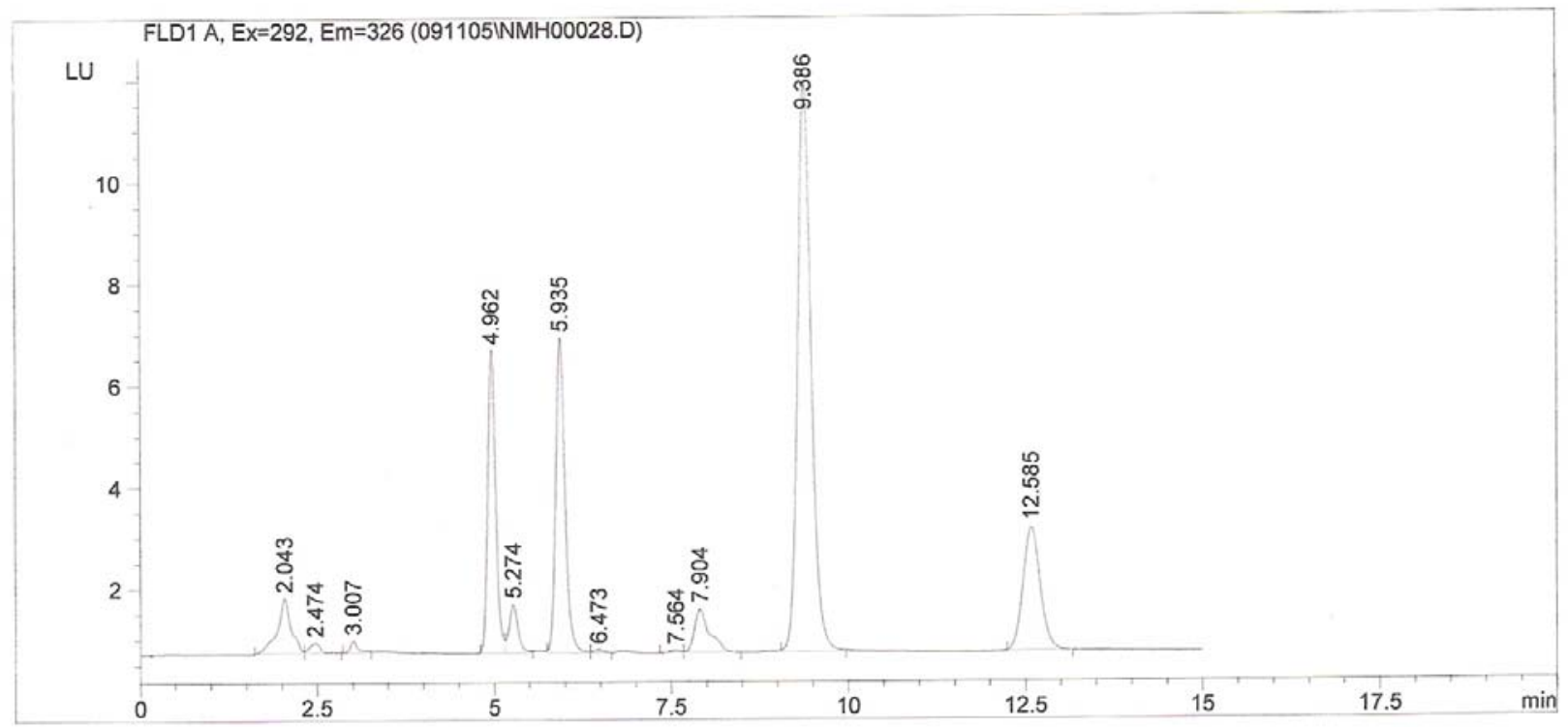

Fig. 2: Typical HPLC chromatogram of crude palm oil

As suggested by de Greyt et al. ${ }^{[14]}$, only at high temperature of $>260^{\circ} \mathrm{C}$, vitamin $\mathrm{E}$ undergo thermal decomposition. Due to the reason that the physical refining was carried out below the temperature, thermal degradation of vitamin E can be prevented. However, the total concentrations were slightly reduced due to possible adsorption on the bleaching earth. It was observed that the $\alpha$-homologues were decreased most significantly after bleaching while the $\gamma-$ homologue reduced after deodorization.
Table 2 shows the percent composition of the vitamin $\mathrm{E}$ in all samples analyzed. It was observed that the composition of all vitamers were similar throughout physical refining. The composition (\%) of $\alpha$-tocomonoenol in CPO was in good agreement with reported data but were different for other vitamers, namely $\alpha-T$ and $\gamma-T_{3}{ }^{[11]}$. Our results are closer to that reported by Hashimoto et al. ${ }^{[3]}$. The difference can be contributed by the possible degradation of $\gamma-\mathrm{T}_{3}$ during sample pretreatment and thus decreasing its amount. 
The direct injection of the samples into HPLC prevents any degradation of the vitamin $\mathrm{E}$ as it was reported that

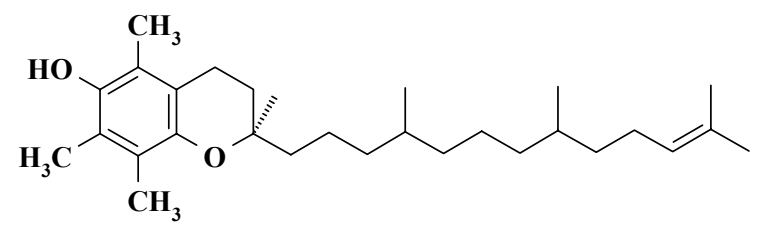

Fig. 3: Molecular structure of $\alpha$-tocomonoenol

vitamin $\mathrm{E}$ decomposes easily in the presence of light and oxygen ${ }^{[1]}$. This study is the first to report the quantification of $\alpha$-tocomonoenol during physical refining of palm oil. The results showed that the composition (\%) of the vitamin $\mathrm{E}$ during refining were similar to that of CPO.

The HPLC method described in this work provided fast and valuable information of the vitamin $\mathrm{E}$ in the oils with minimal analysis time and no sample pretreatment.

\section{ACKNOWLEDGEMENTS}

The authors wish to thank the Director General of Malaysian Palm Oil Board for his permission to publish this paper. Chiew Wei Puah would like to thank MPOB for financial support to conduct her Ph.D. research.

\section{REFERENCES}

1. Bramley, P.M., I. Elmadfa, A. Kafatos, F.J. Kelly, Y. Manios, H.E. Roxborough, W. Schuch, P.J.A. Sheehy and K-H. Wagner, 2000. Vitamin E. J. Sci. Food Agric., 80: 913-938.

2. Goh, S.H., Y.M. Choo and S.H. Ong, 1985. Minor constituents of palm oil. J. Am. Oil Chem. Soc., 62: $237-240$.

3. Hashimoto, T., A. Kato, K. Tanabe, H. Mamuro, M. Yamaoka, K.G. Berger and M.T. Abd. Gapor, 1980. Studies on tocopherols and tocotrienols in Malaysian palm oil. Proc. Intl. Symp. on the Advanced Industrial Utilization of the Tropical Plants, 1-4 Sept.. Tsukuba, Japan. International Research and Development Cooperation Division, Ministry of International Trade and Industry, Japan.
4. Packer, L., 1991. Protective role of vitamin E in biological systems. Am. J. Clin. Nutri., 53: 1050S$1051 \mathrm{~S}$.

5. Traber, M.G., M. Podda, C. Weber, J. Thiele, M. Rallis and L. Packer, 1997. Diet-derived and topically applied tocotrienols accumulate in skin and protect the tissue against ultraviolet lightinduced oxidative stress. Asia Pacific J. Clin. Nutr., 6: 63-67.

6. Sundram, K., H.T. Khor, A.S.H. Ong and R. Pathmanathan, 1989. Effect of dietary palm oils on mammary carcinogenesis in female rats induced by 7,12-dimethylbenz(a)anthracene. Cancer Res., 49: 1447-1451.

7. Goh, S.H., N.F. Hew, M. Yadav and A.W. Norhanom, 1994. Inhibiton of tumour promotion by various palm oil tocotrienols. Int. J. Cancer, 57: 529-531.

8. Matsumoto, A., S. Takahashi, K. Nakano and S. Kijima, 1995. Identification of a new vitamin $E$ in a plant oil. J. Jap. Oil Chem. Soc., 44: 593-597.

9. Abidi, S.L., 2003. Tocol-derived minor constituents in selected plant seed oils. J. Am. Oil Chem. Soc., 80: 327-333.

10. Slover, H.T., R.H.JR. Thompson and G.V. Merola, 1983. Determination of tocopherols and sterols by capillary gas chromatography. J. Am. Oil Chem. Soc., 60: 1524-1528.

11. Ng, M.H., Y.M. Choo, A.N. Ma, C.H. Chuah and H. Mohd. Ali, 2004. Separation of vitamin E (tocopherol, tocotrienol and tocomonoenol) in palm oil. Lipids, 39: 1031-1035.

12. Rossi, M., M. Gianazza, C. Alamprese and F. Stanga, 2001. The effect of bleaching and physical refining on color and minor components of palm oil. J. Am. Chem. Soc., 78: 1051-1055.

13. Yamamoto, Y., N. Maita, A. Fujisawa, J. Takashima, Y. Ishii and W.C. Dunlap, 1999. A new vitamin $E$ ( $\alpha$-tocomonoenol) from eggs of the pacific salmon Oncorhynchus keta. J. Nat. Prod., 62: 1685-1687.

14. De Greyt, W.F., M.J. Kellens and A.D. Huyghebaert, 1999. Effect of physical refining on selected minor components in vegetable oils. Lipid, 101: 428-432. 